\title{
Analysis of Students' Difficulties in Solving Trigonometry Problems
}

\author{
Rahmatya Nurmeidina ${ }^{1}$, Dina Rafidiyah ${ }^{2}$ \\ $\left\{\underline{\text { rahmatya.dina@gmail.com }}{ }^{1}\right.$, rafidiyahdina@yahoo.com $\left.{ }^{2}\right\}$ \\ Universitas Muhammadiyah Banjarmasin, Barito Kuala, Indonesia ${ }^{1,2}$
}

\begin{abstract}
This study aimed to describe the difficulties of students in solving math problems, especially in solving trigonometry questions.. The subjects of this study were freshmen majoring math program who had already taken trigonometry courses. The research type was qualitative descriptive research. Data collection tools were essay trigonometry tests, deep interviews and documentation. Data analysis techniques were carried out using document analysis techniques. The results show that the students have difficulty in understanding the information given to solve the problems. They do many errors in applying trigonometric concepts to answer the questions, because they do not calculate correctly the results of angle comparison. Besides, they incorrectly determine the angle of comparison between the angles obtained. Furthermore, the students were not familiar with the trigonometry questions because they were confused.This problem has hindered them from accomplishing the task in a given time.
\end{abstract}

Keywords: Difficulty Analysis, Trigonometry, Mathematics Education Students, Problem Solving.

\section{Introduction}

Problem solving ability is one of the soft skills that students should have in learning mathematics. It is an essential part of the learning process [1]. Therefore, students need to be able to formulate and solve complex problems [2], so they can acquire ways of thinking, habits of persistence and curiosity, also self confidence to solve other problems in the real life. A question will be a problem for someone only if the question remains unsolved even though he or she knows the way to solve it.

The problem solving process requires systematic, logically planned activities, including appropriate strategies and selection of appropriate implementation methods. There are two types of problems in math. First is that routine problems, refers to simple problems related to solving mathematical problems. Technically, arithmetic abilities that involves four basic operations in mathematics (addition, subtraction, multiplication and division), direct applications using 
formulas, laws, theorems and mathematical equations, are generally common mathematical problems. The second is non-routine problems or unique problems, that require applications and skills, concepts or principles in solving them. Solving non-routine mathematical problems does not require a text book based answer and the answers could be relatively varied [3].

When it comes to several difficulties in problem solving that the students faced, namely: 1) They could not understand the mathematical sentences; 2) They couldn't figure out the necessary information to solve the problem; 3 ) They tend to guess the answers without any thinking process; 4) They tend to be impatient reading mathematical problems; and 5) They do not like to read long problems [4]. Those kinds of problems usually happen to new students in math majors. Some of them try to seek help to overcome those problems, but some are just happy with the situations .

There are difficulties in resolving mathematical problems, as follows: 1) the students cannot understand the language of mathematics; 2) the students cannot understand mathematical concepts; 3) the student cannot make plan to solve the problem; 4) the students do not have enough experience and skills in solving mathematical problems; 5) the students hesitate to understand the purpose of the question; 6) the answers are less accurate due to error in writing or counting; and 7) the students have less motivation to solve the problems [3].

Based on the explanation above, it can be concluded that the types of difficulties in solving mathematical problems are difficulties in understanding mathematical questions or understanding the information provided to solve problems, difficulties in using concepts (conceptual errors), difficulty in counting, inaccuracy, lack of experience and skills in completion problems and lack of motivation in solving mathematical problems.

Trigonometry is a very important subject in mathematics. It is a subject that is taught in schools and a basic concept that are also used in other subjects such as geometric, algebraic and graphical ways of thinking [5]. It helps students develop cognitive strategies, such as problem solving through reasoning and proofing capabilities of the students [4]. It makes the students follow up with complex numbers, limits, derivatives, and integrals. Therefore, problem solving in trigonometry may be considered very difficult for high school students, also for teacher candidate to master [6] and [7].

There are several research related to analyzing problem solving in trigonometry problems. One of which is that a study of 80 senior secondary students in Nigeria. The researchers used the Mathematics Achievement Test (MAT) and the Trigonometry Diagnostic Test (TDT) to investigate the type of errors that were done by the students. The results indicated that students still struggled to solve trigonometry problems. Also, the teacher should give more opportunities for students to do regular problems, and concentrate to solve problems one step at the time. The researchers suggest that this study has to be expanded in different level of education [8].

Solving math problems including trigonometry needs IDEAL problem solver, such as identifying problems, defining the problem, exploring solution, acting on strategies, and looking back \& evaluate [9]. The students must follow those steps so they can handle the math problems. It is very important to understand, how the students solve their math problems, so the teacher can give some suggestions. Hopefully, in the future they can solve more math problems or even in their daily problems using logic. 
Therefore, this study is to find out about the difficulties of students in solving trigonometry problem solving questions. This is important for the lecturers, so they can pay more attention to overcome the problems and emphasize the steps that are usually carried out in a situation and look for ways to sharpen student skills in solving problems. In addition, so that the students can find out what difficulties and mistakes are often found and they do not repeat the same mistakes in the future.

\section{Method}

This study used descriptive qualitative research to describe how students answer the trigonometry problems This method gets information about the "human" side of an issue [10], so we can gain many factors that affect students' abilities to solve the problems. The data of this study were the answers of trigonometry submitted by seven students majoring in math study program and had already took their trigonometry class. The procedure of data collection were through: 1 . The students answered four trigonometry essay problems, 2. Deep interview about the students' difficulties in answering the problems given, and 3. Documentation of all data. Document analysis was used as a systematic procedure for reviewing or evaluating documents [11]. The interview will enrich the data collection and the analysis of the documents to know more about how the students solve the problems [12].

\section{Results}

Based on Table 1, it is found that $25 \%$ of errors are due to mathematical statements, $32 \%$ due to concept errors and $7 \%$ due to calculate errors.

Table 1. Table of Error Analysis.

\begin{tabular}{|c|c|c|c|c|c|c|}
\hline \multirow{2}{*}{ Kind of students' mistakes } & \multicolumn{4}{|c|}{ Questions } & \multirow{2}{*}{ Total } & \multirow{2}{*}{$\%$} \\
\hline & 1 & 2 & 3 & 4 & & \\
\hline Mathematical statement & 4 & 0 & 3 & 0 & 7 & $25 \%$ \\
\hline Concept & 2 & 1 & 4 & 2 & 9 & $32 \%$ \\
\hline Error calculation & 0 & 1 & 0 & 1 & 2 & $7 \%$ \\
\hline
\end{tabular}




\subsection{First Question}

- In the $\mathrm{ABC}$ triangle, the length of side $\mathrm{A}$ is $8 \mathrm{~cm}$ longer than that of $1 / 2$ of side $\mathrm{B}$ and the length of side $\mathrm{C}$ is $2 \mathrm{~cm}$ shorter than that of $3 / 4$ of side $\mathrm{A}$. If the circumference of the $\mathrm{ABC}$ triangle is $42 \mathrm{~cm}$. Please count:

1) The length of side $A$, side $B$, and side $C$

2) The area of the $\mathrm{ABC}$ triangle.

- The students' answers analysis:

1) Based on the analysis that has been carried out on the answers to the student's description tests, it was found that four students had difficulties in understanding mathematical statements (Fig. 1).

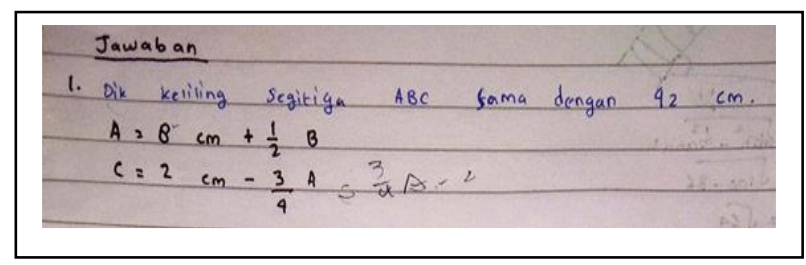

Fig. 1. First student's answer for first question

2) Two students had difficulties understanding the concept or the intent of mathematical statements, but were wrong in using the concepts used to complete the description (Fig. 2).

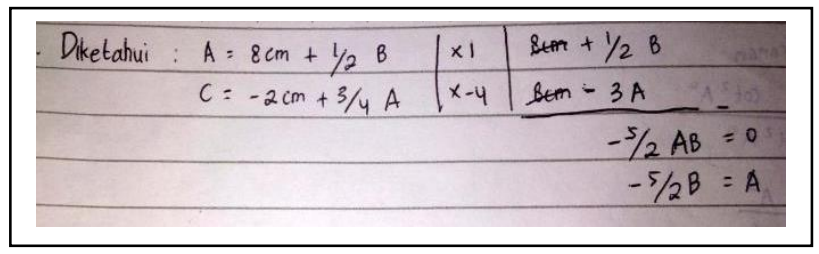

Fig. 2. Second student's answer for first question 
3) One student can understand the mathematical statement and the answer is correct, but he used the method of trying out the length of the side that matches the circumference and the provisions of the question statement (Fig. 3).

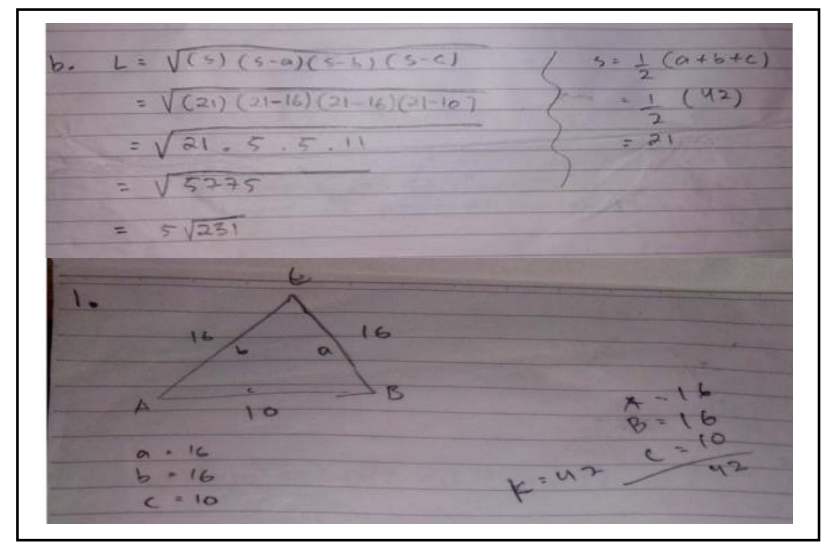

Fig. 3. Third student's answer for first question

\subsection{Second Question}

- $\quad$ Rina, Rani, and Rika play on a soccer field. The position of the three people forms a triangle. The distance between Rina and Rani is 8 meters. The distance between Rani and Rika is 6 meters, and the distance between Rika and Rina is 3 meters. Determine one of the angles formed by the three children.

- The students' answers analysis:

1) Four people answered correctly the math problems. One person had difficulties in understanding the concept (Fig. 4).

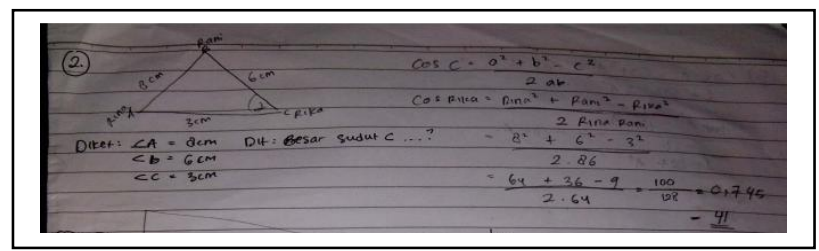

Fig. 4. First student's answer for second question 
2) One person understood the problem and the concept, but it was wrong to conclude the angle (Fig. 5).

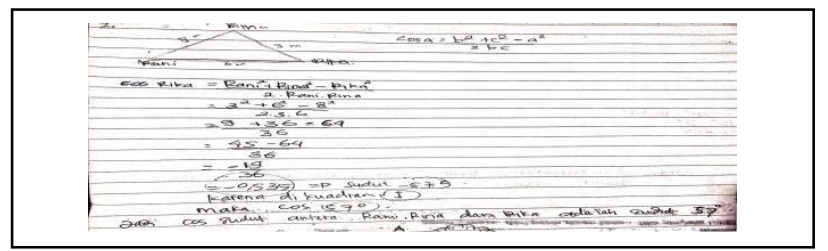

Fig. 5. Second student's answer for second question

3) One person understood the problem and concept, but was not careful in calculating (Fig. 6).

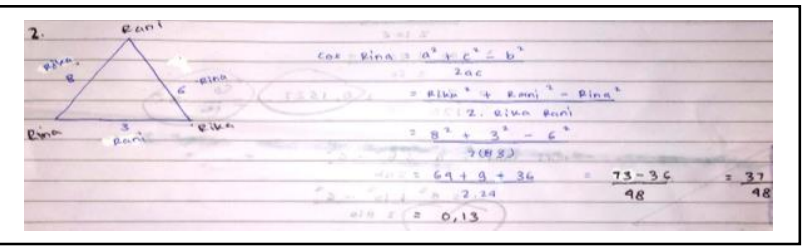

Fig. 6. Third student's answer for second question

\subsection{Third Question}

- Adi with a height of $1.5 \mathrm{~m}$ will measure the height of the tree. From Ali's spot, the treetop was seen with an angle elevation of $45^{\circ}$ from the point of view of Adi. The horizontal distance from Adi to the tree is $18 \mathrm{~m}$.

1) Make the illustration of the story

2) How long is the height of the tree?

- The students' answers analysis:

1) Three students have difficulty understanding mathematical statements, this can be seen from the illustration that is still wrong (Fig. 7).

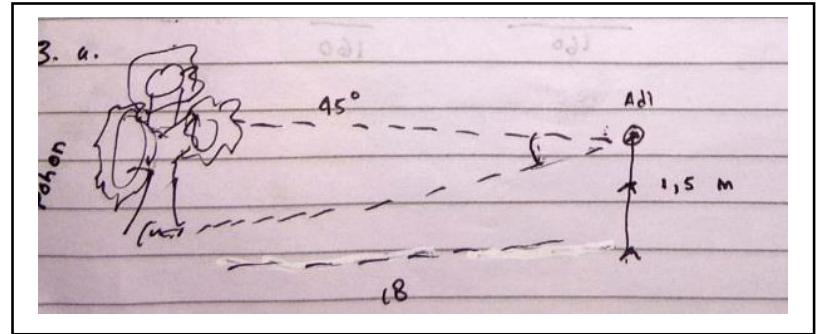

Fig. 7. First student's answer for third question 
2) Four students can understand mathematical statements well shown by being able to draw illustrations correctly, but students are still having difficulty in determining the concept of trigonometric formulas used in solving this question (Fig. 8).

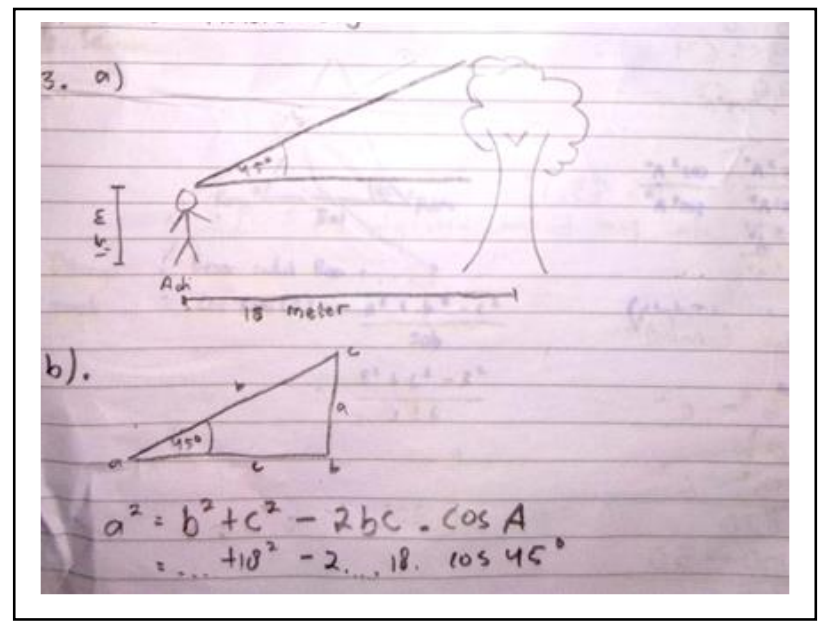

Fig. 8. Second student's answer for third question

\subsection{Fourth Question}

- A ladder laid on a vertical wall. The cusp of the stairs attached to the adobe wall at an altitude of 8 meters of the ground. If the length of the stairs is $10 \mathrm{~m}$, determine the size of the angle formed by:

1) The illustration image

2) Stairs and ground level

3) Stairs and wall

- The students' answers analysis:

1) Four people can solve trigonometric problems correctly. Two people can understand mathematical statements, but still have difficulty understanding mathematical concepts (Fig. 9).

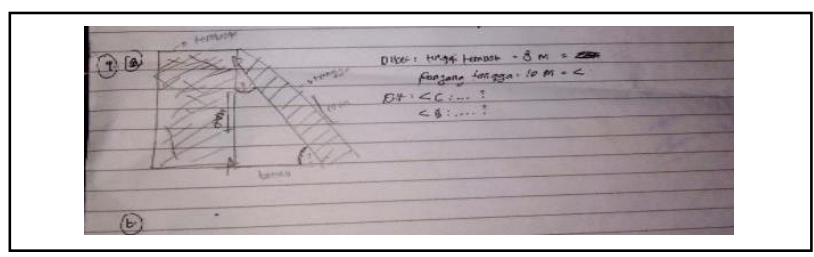

Fig. 9. First student's answer for fourth question 
2) One person can understand mathematical concepts and trigonometric concepts that are used well, but are wrong in the final calculation process (Fig. 10).

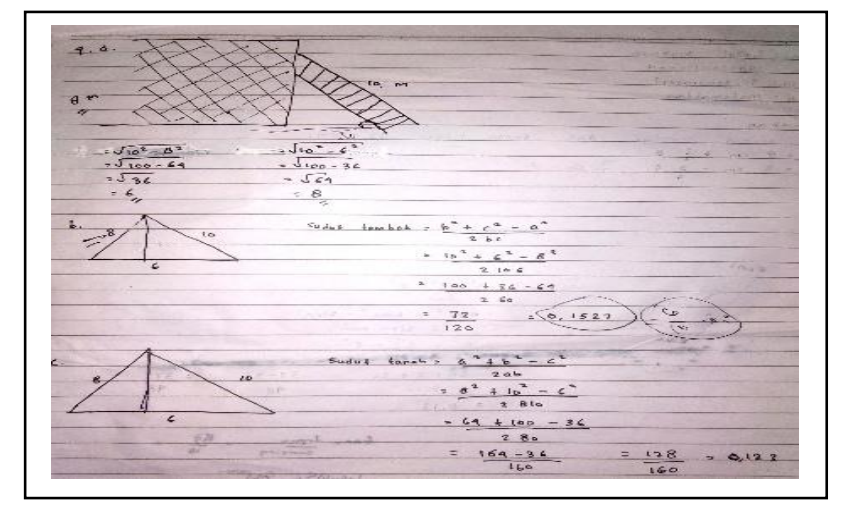

Fig. 10. Second student's answer for fourth question

Based on the results of the interview, it was also known that students still experienced difficultylies in understanding the sentences of mathematical statements. They were confused in choosing the right concepts of trigonometry to solve the problems, so they ran out of time.

The students have not been familiar to solve real life problems. In the classroom, the lecturer focuses more on teaching the discovery of formulas and how the students can use the formula. They should obtain and understand the concept well, not just memorize it. Therefore, problem solving were not trained specifically.

In the trigonometry textbook, there are already problem solving, but the lecturer does not discuss specifically and asked the students to study on their own, discuss it with classmates and ask the teacher for any queries. However, students had low motivation to do it. They gave up before they tried to answer. They prefer working on routine questions to implementing the concepts

\section{Discussion}

The finding from this study were leading to most of the theoretical concept in the beginning of this paper. From the students' answers and the interview, we can gain many understanding about what was happening in the class when the lecturer explained trigonometry concept. We can find the answer also, about what the lecturer should do in the future classes.

The questions were answered by seven students. The first question was quite difficult for them that only had one right answer, but that answer involveed guessing by the students. This is in line with [4] in their research that students tend to guess if they do not know how to solve the math problem. The second and fourth questions were so somehow familiar to the students, so each questions got four right answers. The third one was the most difficult one for the students that no one can answer it. 
The students' difficulty to understand math statements or to apply math concepts appeared in all numbers. Especially, in question number three. The students could not understand math concept and choose the correct trigonometry concept. Followed by other numbers, this situation was also experienced by [4] and [3]. The other problem is that when the students understand the concept but could not apply it, or calculating it wrongly.

The interview showed that, the students had lack of motivation to solve those problems. They just learnt what the lecturer gave them. They also did not practice, even though the lecturer asked them to practice a lot. The common problems of Trigonometry seemed difficult to students [7], because they said that the lecturer never gave them those kinds of questions in the class. The students tend to give up and wait until their lecturer give the explanation.

From that evaluation, we can conclude that the lecturer must bring new perspective to the class that math problems are applicable with logic IDEAL strategies [9]. Therefore, the students can set the way of thinking, so they solve the problems. Later on, if the students have any problems related to math in general or trigonometry in particular they can solve it with confidence.

\section{Conclusion}

The results showed that students had difficulties in understanding the information given to solve the problems. (difficulties in understanding the intent of mathematical statements). That situation has led to errors in applying trigonometry concepts to get the solution of the problem. The students were not careful in calculating the result. The students were not familiar with real life math problems The results of this study can be used as a basis for conducting further research on solving mathematical problems in trigonometry. Lecturers can also use the results of this study to evaluate learning method and how to motivate students to practice mathematical questions, especially trigonometry materials.

Acknowledgments. We thank the students of Mathematics Education, University of Muhammadiyah Banjarmasin who voluntarily become our respondents. Also for the Dean of Teacher Training and Education, University of Muhammadiyah Banjarmasin, who gave us the full support to finish this paper.

\section{References}

[1] Huda WN, Suyitno H. Analysis of mathematical problem solving abilities in terms of students' motivation and learning styles. J Prim Educ. 2017;6(3):209-17.

[2] Dossey JA, Sharon SM, Halvorsen KT. Mathematics education in the United States 2016: A capsule summary fact book. 2016.

[3] In'am A. Menguak penyelesaian masalah matematika (Analisis pendekatan metakognitif dan model polya). $2015.94 \mathrm{p}$.

[4] Phonapichat P, Wongwanich S, Sujiva S. An analysis of elementary school students' difficulties in mathematical problem solving. Procedia - Soc Behav Sci [Internet]. 2014;116(2012):3169-74. Available from: https://linkinghub.elsevier.com/retrieve/pii/S1877042814007459 
[5] Sarac A, Tutak FA. The relationship between teacher efficacy, and students ' trigonometry selfefficacy and achievement. Int J Math Teach Learn. 2017;18(1):66-83.

[6] Ernaningsih Z, Wicasari B. Analysis of mathematical representation , communication and connection in trigonometry. In: The 2017 International Conference on Research in Education. 2017. p. $45-57$.

[7] May V, Courtney S. Developing meaning in trigonometry. Illinois Math Teach. 2016;63(1):25-33.

[8] Usman MH, Hussaini MM. Analysis of Students' Error in Learning of Trigonometry Among Senior Secondary School Students in Zaria Metropolis, Nigeria. IOSR J Math. 2017;13(02):01-4.

[9] Permata LD, Kusmayadi TA, Fitriana L. Mathematical problem solving skills analysis about word problems of linear program using IDEAL problem solver. J Phys Conf Ser. 2018;1108(1).

[10] Mack N, Woodsong C, MacQueen KM, Guest G, Namey E. Qualitative research methods: A data collector's field guide [Internet]. Family Health International. 2011. 1-137 p. Available from: http://r4d.dfid.gov.uk/Output/188391/Default.aspx\%0Ahttp://ebooks.cambridge.org/ref/id/CBO97 81107415324A009\%0Ahttps://www.fhi360.org/sites/default/files/media/documents/Qualitative Research Methods - A Data Collector's Field Guide.pdf

[11] Bowen GA. Document analysis as a qualitative research method. Qual Res J [Internet]. 2009;9(2):27-40. Available from: http://www.emeraldinsight.com/doi/10.3316/QRJ0902027

[12] Rubin HJ, Rubin IS. Qualitative Interviewing - The Art of Hearing Data. 2 Edition. Bragason EH, editor. SAGE Publications. London, New York: Thousand Oaks; 2005. 